\title{
Research on Geotechnical Engineering Technique Innovation Method in Loess Region
}

\author{
Jia Yajun ${ }^{1,2}$, Chen Cunli ${ }^{1}$, Zhang Huyuan ${ }^{3}$, Liu Naijun ${ }^{2}$ \\ ${ }^{1}$ Civil Engineering and Architecture Institute, Xi'an University of Technology , Xi'an 710048, China \\ ${ }^{2}$ Gansu Forestry Technological College ,Tianshui ,Gansu 741020, China \\ ${ }^{3}$ Lanzhou University, Lanzhou, Gansu 730000, China
}

Keywords: Geotechnical Engineering, New Methods, Three-Dimensional Digital Technology

\begin{abstract}
As urbanization continues to accelerate the development, construction projects are gradually increasing, and geotechnical engineering technology is constantly attention. Because the technology is directly related to geotechnical engineering building high-speed rail, bridges, tunnels and other projects, these projects are closely related to people and travel. In the project implementation process, we need to ensure the quality of geotechnical engineering projects completed by theoretical analysis and a lot of practice. The rapid development of science and technology, geotechnical engineering and technical innovation to provide a lot of favorable conditions in the project implementation of the project has also found a lot of innovative ways. Geotechnical engineering in the future to keep social competition advantages, we must change the previous development model, to achieve innovative development, namely in the development of attention to the protection of the natural environment persist, the economic development model sound and rapid development.
\end{abstract}

\section{Theoretical Introduction of Geotechnical Engineering}

Geotechnical engineering mainly using a variety of instruments for geotechnical exploration comprehensive renovation and transformation, and its main research subject is the rock and soil in which the rock in the course of geological changes in the formation of a variety of more complex structures and environmental stress. In different geological and natural environment of rock and soil, main purpose of geotechnical engineering manipulation necessary to maintain stability, and avoid the overall imbalance.

Geotechnical engineering in a wide variety of construction technology, which has a hidden underground construction technology, which mainly refers to the continuous wall and pile foundation construction technology in loess region, in both the construction techniques, not only the construction site completely hidden in the ground, which the construction methods and procedures are also covert. Construction workers and environment is complex. Human factors and environmental factors that affect the construction of the main reason for construction workers, more jobs geotechnical engineering, construction workers on site intensive, personnel-related pre-construction preparation work great. Therefore, the construction and construction environment is complex ${ }^{[1]}$.

Pouring Concrete Large Diameter Pipe Technology Acronym (PCC pile) technology, which is a flexible piles technology, although low cost, easy to spread, but relatively low pile strength to reinforcement depth is limited and difficult to control settlement after construction. Although the high strength rigid pile, reinforcement depth large enough, but the high cost of cost, easy to large scale.

\section{Technological Difficulties of Geotechnical Engineering}

Today, development of geotechnical engineering in loess region bottlenecks, so our relationship at this stage must be combined with various aspects of geotechnical engineering and environmental factors more closely, we at the same time to develop the national economy, but also varying degrees 
of damage to the environment around us. Therefore, as the architecture and construction of the Earth directly linked to geotechnical engineering, should play an important role in the future in environmental remediation ${ }^{[2]}$. Fig.1 shows the difficulties geotechnical engineering technology.

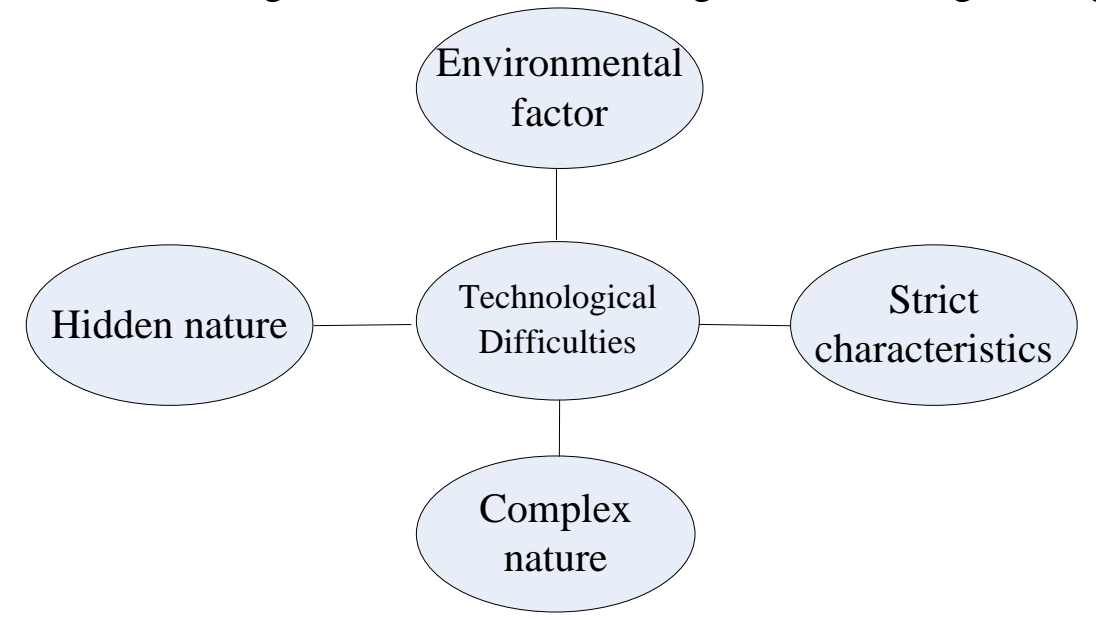

Fig. 1.The difficulties geotechnical engineering technology

Geotechnical construction including a variety of technical methods wherein pile, diaphragm wall, and all hidden in the ground, and each step of the construction and construction sectors are also under covert conditions completed. Construction workers usually limited by many factors and the environment during construction. This is because there are various types during construction, appropriate personnel and carrying out more intensive assignments to be prepared before the concrete construction is relatively large, however, the job in engineering field survey carried out and the specific instrument Further devices are relatively light and flexible, technology in the construction can not contain exact match type of pile, we need to analyze specific issues. Geotechnical engineering during the construction of a certain rigor, such as: the construction applied perfusion column except for the pillar structure, the pillar material strength has strict requirements, the requirements are quite detailed deviation.

At the construction site, in order to facilitate the technical staff survey, jobs, reduce the workload, all equipment must be light and flexible as possible, in order to analyze specific technical skill and pile type matching. In construction perfusion column, for example, not only to the stringent requirements of pillar strength of the material, but also the strict requirements of the pillar structure, detailed requirements bias, reflecting the stringency of geotechnical engineering. Expressway bridgehead bumping geotechnical engineering technology is not just our problem, but also a troubled construction problem of the world. Bridgehead Bump causes two things: soil has great compressibility, soft soil bearing capacity difference; when on a high embankment fill, will lead to significant and severe soil ${ }^{[3]}$.

\section{Sustainable Development Excavation Technology}

From the point of view of the combination member, supporting structure and the main structure of the combination of three types, namely, the external walls of the basement wall and envelope combination of horizontal structural member and horizontal slab support system combining vertical structural member and supporting structure for the vertical support systems combined. According to the extent of supporting structure in combination with the main structure to distinguish, the supporting structure can be combined with the main structure works grouped into three types, namely underground continuous wall surrounding the two-in-one combination of the pit wall support system using temporary construction practices along the periphery provisional envelope binding pit slab system level support alternative uses reverse construction, supporting structure and the main structure using a combination of comprehensive reverse construction.

TRD construction method (trench cutting re-mixing deep wall) with conventional SMW method vertical axis longitudinal cutting and stirring construction in different ways, it first chain 
saw type cutting tool insert foundation excavation to wall design depth, and then injected into the curing agent, mixed with the soil in situ and lateral excavation continued, stirring, the level of progress ${ }^{[4]}$. Fig. 2 shows the construction process of the TRD method.

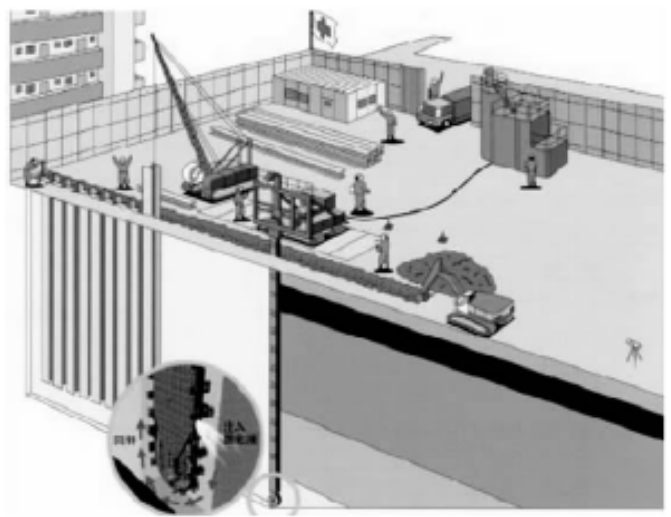

Fig. 2 .The construction process of the TRD method

Conventional methods of supporting the use of temporary retaining body sealing envelope, set the level of multi-channel support or anchor. Provisional Envelope body include the huge cost of bored piles, and its basement after construction is completed, quit working and discarded in the ground, causing a great waste of material. Compared with the traditional method of deep excavation embodiment, the supporting structure and the main structure of the combination of technology has to protect the environment, save social resources, shorten the construction period and many other advantages, in line with the national energy saving development strategy is sustainable development effective urban underground space technology development and construction of a conservation-oriented society.

\section{Three-Dimensional Digital Technology}

Because of the complexity of the urban underground engineering, invisibility and uncertainty in recent years, with the continuous development of information technology, at home and abroad in the field of digital underground engineering carried out a series of studies, the use of information technology for underground engineering geology description, analysis, design, construction and operation and maintenance of the establishment of the adaptive system updated in real time. In this respect at home and abroad has made certain achievements, the technology can be effectively utilized all existing information, to solve the problem of insufficient information ${ }^{[5]}$.

Digital Underground Space Information System "has a good openness and compatibility, using the international mainstream and mature technology, reliability and safety, easy to maintain, with existing systems and interfaces to meet the network and multimedia technology . the basic needs of the system integration of data hold include: urban terrain data (status map or topographic map), geological data (borehole data, physical properties, mechanical properties, etc.), underground structure data (buried pipelines, underground, shaft, etc.) construction information and site monitoring results obtained shield tunnel, etc. This information can all be unified with database management digitized. users can access the system via the Internet locally.

Tunnel tunnel structure is based on the measurement data in the display state of the segment of the assembled three-dimensional graphics. In addition to the information in the tunnel, a variety of monitoring data is also integrated in this system, use the tunnel maintenance management information may be added in the present system. Formation within the model plus a three-dimensional model of underground space under the tunnel structure diagram. Fig.3 shows the application of three-dimensional digital technology. 


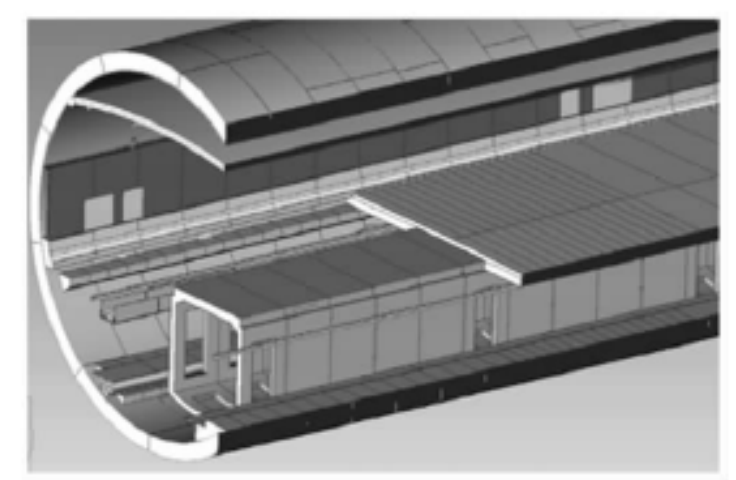

Fig. 3 .The application of three-dimensional digital technology

\section{Conclusions}

With the rapid development of science and technology, people pay attention to the degree of geotechnical engineering is also gradually improved. The use of science and technology in the construction and implementation of geotechnical engineering in the process of innovation a lot of ways, but also achieved some results. Geotechnical engineering and technical innovations continue to increase, new ideas and thoughts in the course of their work formed the need for timely communication in order to continue the practice in innovative ways to improve the technical level of the staff. Geotechnical engineering technology requires a combination of modern science and technology for continuous innovation and research combined with practical activities according to our needs. In addition to the technical presentations, as well as computer technology and in situ testing techniques in geotechnical engineering project implementation process has a certain application, and has made more significant effect.

\section{Acknowledgements}

Scientific research project of college in Gansu(2015A-188); The science and technology support program Foundation of Tianshui (No. 2015-25);

Gansu Education Science Planning Office (GS[2013]GHBZ092)

\section{References}

[1] Zhu H H, Li X Y, Ge J K, et al. Study on steel pipe mechanism during culvert box extruding into soft soil, ASCE Geotechnical Special Publication on Tunneling and Underground Construction [C], Geo Shanghai Conference, 2006.

[2] Theory of economic development [M]. DU Zhen-xu, ZHENG Li-ping, LIU Yu-gang, translators Beijing China Commercial Publishing House, 2009.

[3] LIU Han-long, GAO Yu-feng, MA Xiao-hui. A concrete quickly pouring device and its construction method of large diameter cast-in-place pipe pile: China, ZL200810019690.X [P]. 2009-12-02.

[4] MAKRODIMOPOULOS A. Remarks on some properties of conic yield restrictions in limit analysis [J]. International Journal for Numerical Methods in Biomedical Engineering, 2010, 26 (11):1449-1461.

[5] Technical specification for composite foundation of cast-in-place[S]. Beijing China Architecture \& Building Press, 2010. 